\title{
A monometallic iron(I) organoferrate
}

\author{
Fedor E. Zhurkin, $†$ Matthew D. Wodrich, $†$ and Xile Hu†* \\ † Institute of Chemical Sciences and Engineering, Ecole Polytechnique Fédérale de Lausanne (EPFL), 1015 Lausanne, \\ Switzerland \\ Supporting Information Placeholder
}

ABSTRACT: Tetra- $n$-butylammonium (TBA) ( $\eta^{6}$-biphenyl)diphenylferrate was formed unexpectedly in the reaction of $(\mathrm{TBA})_{2}\left[\mathrm{Fe}_{4} \mathrm{~S}_{4} \mathrm{Cl}_{4}\right]$ with an excess of phenyllithium. This complex belongs to a novel type of organoferrates.

Organoferrates are anionic organometallic iron complexes. ${ }^{1}$ They are invoked as important intermediates in many ironcatalyzed organic reactions. ${ }^{1,2}$ Organoferrates devoid of stabilizing ligands (non-stabilized organoferrates) are scarce. ${ }^{2}$ Reported examples include tetramethyl- $\left(\mathbf{1},{ }^{3}\right.$ Scheme 1$)$ and tetrabenzylferrates(III) (2) ${ }^{4},\left[\mathrm{Fe}(\mathrm{Mes})_{3}\right]^{-}(\mathbf{3 a})^{5}$ and $\left[\mathrm{FeBn}_{3}\right]^{-}$ (3b), ${ }^{4}$ tetramethyl and tetraphenyl iron(II) complexes $\mathbf{4}$ and $\mathbf{5},{ }^{2}$ a tetraphenyl dihydride complex $6{ }^{6}$ an $\mathrm{Fe}(0)$ complex $7{ }^{7}$ formally $\mathrm{Fe}(-\mathrm{II})$ complexes $\mathbf{8}$ and $\mathbf{9},{ }^{8}$ and an octanuclear ferrate $\left[\mathrm{MgCl}(\mathrm{thf})_{5}\right]\left[\mathrm{Fe}_{8} \mathrm{Me}_{12}\right] .^{9}$

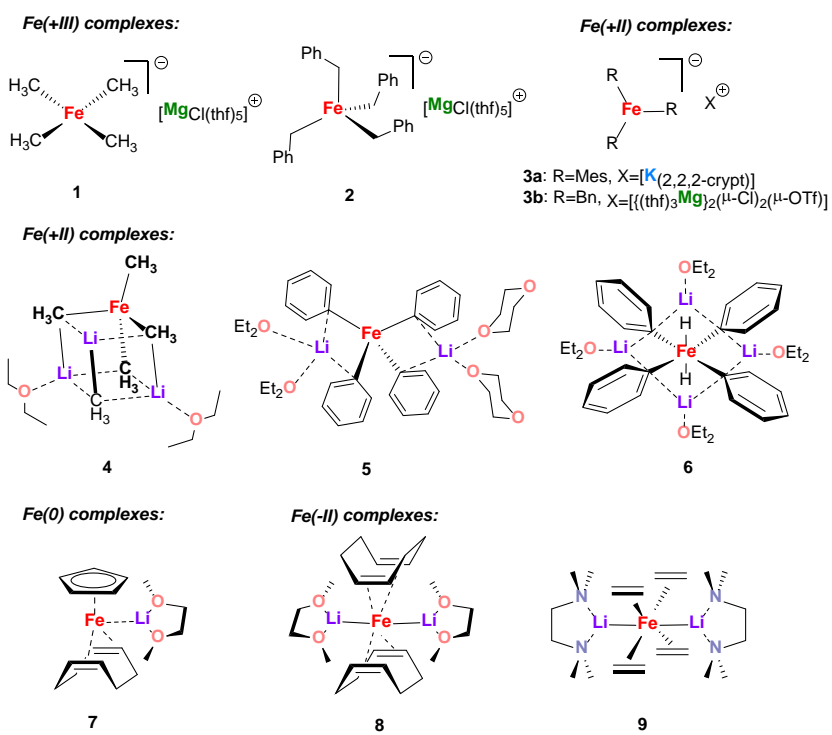

Scheme 1. Representative examples of non-stabilized organoferrates.

With exception of $\mathbf{1 - 3 b}$, these complexes often contain either direct Fe-metal (most often Fe-Li) interactions, or solvated metal cation(s) (most often lithium) in the proximity of the iron center. The latter usually forms short contact with the ipso-carbons of the organic ligands. Moreover, the oxidation states of iron in known organoferrates are limited to +III, +II, 0, and -II. Here we report a novel Fe(I) organoferrate which is unsupported by either another metal cation or a heteroatom-based ligand.
Inoue and co-workers studied catalytic activity of phenyllithium-treated cluster $\left[\mathrm{Fe}_{4} \mathrm{~S}_{4} \mathrm{Cl}_{4}\right]^{2-}$ in hydrogenation reactions. They prepared the catalyst by addition of $(\mathrm{TBA})_{2}\left[\mathrm{Fe}_{4} \mathrm{~S}_{4} \mathrm{Cl}_{4}\right](\mathbf{1 0}$, TBA $=$ tetra- $n$-butylammonium) to $\mathrm{a}$ solution of PhLi. This catalyst was active for hydrogenation of some olefins and carbonyl compounds. ${ }^{10,11}$ In an attempt to isolate and characterize the active species in this system, we reacted (TBA) $)_{2}\left[\mathrm{Fe}_{4} \mathrm{~S}_{4} \mathrm{Cl}_{4}\right]$ with 8 equiv. of $\mathrm{PhLi}$ in ether under an inert atmosphere at room temperature (Scheme 2). In the first 1-2 min after PhLi addition, the color of the liquid phase turned into intense orange-black. As the reaction proceeded a black precipitate was formed (11) and the solution became nearly colorless. The precipitate could be dissolved in THF to yield a bloody-red-colored solution. Slow diffusion of pentane into this solution yielded black needle-shaped crystals.

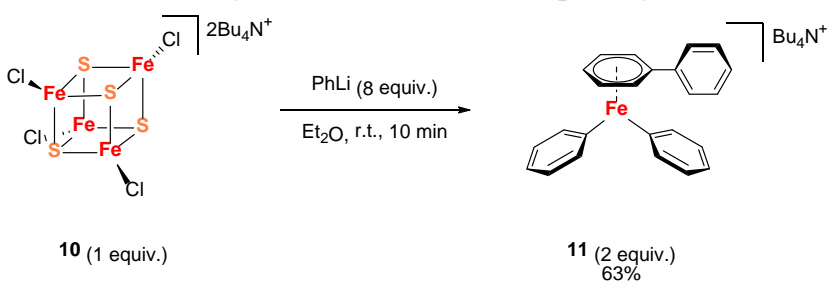

Scheme 2. Synthesis of complex 11.

$\mathrm{X}$-ray crystallography revealed the molecular structure of $\mathbf{1 1}$ (Figure 1). The compound is a TBA salt of an iron(I) complex anion, which is coordinated by a $\pi$-bound $\eta^{6}$-biphenyl ligand and two $\sigma$-bound phenyl ligands. The $\mathrm{Fe}-\mathrm{C}\left(\eta^{1}-\mathrm{Ph}\right)$ distance (1.971-1.977 $\AA$, see Supporting Information) in complex 11 is slightly shorter than its counterpart in $\mathbf{5}$ (2.084-2.216 $\AA)^{2}$ and $6(2.056 \AA) .{ }^{6}$ The distance between the $\mathrm{Fe}(\mathrm{I})$ center and the $\eta^{6}$ phenyl ring $(1.578 \AA$ ) is in line with the values reported for $(\eta$ arene)(Cp)iron(II) complexes. ${ }^{12,13}$ It is remarkable that despite the presence of lithium ion and diethyl ether in the reaction mixture, neither is present in complex 11. Formation of a $\eta^{6}$ biphenyl iron(0) complex upon reaction of an iron(II) bisphosphine complex with phenyl nucleophiles, which proceeds through reductive elimination, has been reported. ${ }^{14}$ Complex 11 might be formed in a similar process via an $\mathrm{Fe}(\mathrm{III})$ tetraphenyl intermediate.

Complex $\mathbf{1 1}$ is paramagnetic. The solution magnetic moment in THF is 1.75 Bohr magneton, determined by the 
Evans' method and after diamagnetic corrections. This value is consistent with a low spin $\mathrm{Fe}(\mathrm{I})$ center $(\mathrm{S}=1 / 2)$. DFT computations at the OPBE/def2-TZVPP levels confirmed the doublet spin multiplicity for the ground state of $\mathbf{1 1}$. The quartet state was found to be $19.8 \mathrm{kcal} / \mathrm{mol}$ higher in energy. Moreover, the optimized geometry of the quartet spin multiplicity deviates significantly from the crystal structure in Figure 1 . An $\mathrm{Fe}(\mathrm{I}) \mathrm{S}=1 / 2$ species was previously observed by electron paramagnetic resonance (EPR), but not isolated, in the reaction of $\mathrm{FeCl}_{3}$ with 4 -tolylMgBr at $-30^{\circ} \mathrm{C}$. ${ }^{4}$ The $\mathrm{N}$ and $\mathrm{H}$ contents determined by elemental analysis agree with the formula of 11; however, the $\mathrm{C}$ content is lower than predicted, despite repetitive measurements, including on single crystals. This discrepancy might be due to decomposition of the complex during elemental analysis. The $\mathrm{Fe}$ content, determined by inductively-coupled plasma atomic emission spectroscopy (ICP-AES), also agrees with the theoretical formula.

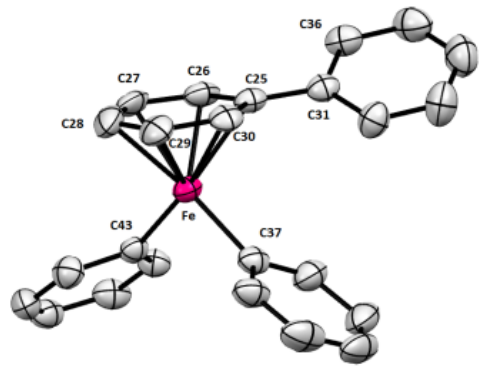

Figure 1. X-Ray crystal structure of the $\left(\eta^{6}\right.$-biphenyl)diphenylferrate anion in complex 11. Two molecules were found in one asymmetric unit of 11; only one of them is shown. The TBA cation and hydrogen atoms are omitted for clarity. The ellipsoids are drawn at a 50\% probability level.

Attempts were made to look for alternative conditions for the synthesis of complex 11. The reaction solvent could be changed to benzene. However, the iron precursor was limited to 10. Replacing $\mathbf{1 0}$ with simpler iron salts such as $\mathrm{FeCl}_{3}$, $\mathrm{FeCl}_{2}$ or $\mathrm{TBA}\left[\mathrm{FeCl}_{4}\right]$ failed to yield complex 11. In fact, reactions of iron salts with $\mathrm{PhLi}$ were previously widely studied, ${ }^{2,6,15}$ but the formation of complex 11 in these systems is hitherto unknown.

Complex 11 is insoluble in hydrocarbon solvents and 1,4dioxane, but shows good solubility in THF and acetonitrile. It does not react with $\mathrm{H}_{2}$ or catalyzes hydrogenation of cisstilbene, ruling out its role as the active species in the hydrogenation system of Inoue. ${ }^{10}$ Reactions of $\mathbf{1 1}$ with CO, $\mathrm{CO}_{2}$ or air led to its decomposition, with concomitant formation of free biphenyl. No reaction occurred with chlorobenzene. However, 11 reacted with 2-bromopyridine, $p$ bromoanisole or 1-bromobutane (see Supporting Information) to give corresponding C-C coupling products (eq 1), albeit in low yields. Biphenyl was also formed.

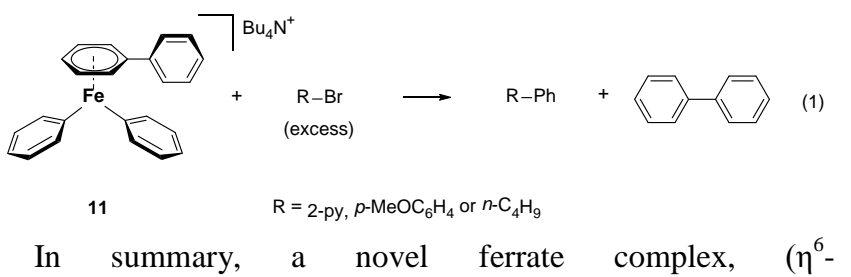
biphenyl)diphenylferrate, was isolated. This complex is neither supported by an alkali metal ion, nor supported by a heteroatom ligand, making it an unique Fe(I) ferrate.

\section{ASSOCIATED CONTENT}

\section{Supporting Information}

The Supporting Information is available free of charge on the ACS Publications website: Experimental procedures and characterization of complex 11 (PDF); Crystallographic data for complex 11 (CIF); DFT computations.

\section{AUTHOR INFORMATION}

\section{Corresponding Author}

*E-mail: xile.hu@epfl.ch

The authors declare no competing financial interests.

\section{ACKNOWLEDGMENT}

This work is supported by EPFL and an ERC starting grant (no. 257096). We thank Drs. Rosario Scopelliti and Farzaneh Fadaei (EPFL) for the X-ray crystallographic study of complex 11. The Laboratory for Computational Molecular Design (EPFL) is acknowledged for providing computational resources.

\section{REFERENCES}

(1) Jegelka, M.; Plietker, B., Catalysis by Means of Complex Ferrates. In Iron Catalysis: Fundamentals and Applications, Plietker, B., Ed. Springer Berlin Heidelberg: Berlin, Heidelberg, 2011; pp 177213.

(2) Fürstner, A.; Martin, R.; Krause, H.; Seidel, G.; Goddard, R.; Lehmann, C. W. J. Am. Chem. Soc. 2008, 130, 8773-8787.

(3) Al-Afyouni, M.H.; Fillman, K.; Brennessel, W.W.; Neidig, M.L. J. Am. Chem. Soc. 2014, 136, 15457-15460.

(4) Bedford, R.B.; Brenner, P.B.; Carter, E.; Cogswell, P.M.; Haddow, M.F.; Harvey, J.N.; Murphy, D.M.; Nunn, J.; Woodall, C.H. Angew. Chem. Int. Ed. 2014, 53, 1804-1808.

(5) Irwin, M.; Jenkins, R.K.; Denning, M.S.; Krämer, T.; Grandjean, F.; Long, G.J.; Herchel, R.; McGrady, J.E.; Goicoechea, J.M. Inorg. Chem. 2010, 49, 6160-6171.

(6) Bazhenova, T. A.; Kachapina, L. M.; Shilov, A. E.; Antipin, M. Y.; Struchkov, Y. T. J. Organomet. Chem. 1992, 428, 107-123.

(7) Jonas, K.; Krüger, C. Angew. Chem. Int. Ed. 1980, 19, 520537.

(8) Jonas, K.; Schieferstein, L.; Krüger, C.; Tsay, Y.-H. Angew. Chem. Int. Ed. 1979, 18, 550-551.

(9) Munoz III, S.B.; Daifuku, S.L.; Brennessel, W.W.; Neidig, M.L. J. Am. Chem. Soc. 2016, 138, 7492-7495.

(10) Inoue, H.; Suzuki, M. J. Chem. Soc., Chem. Commun. 1980, 817-818.

(11) Inoue, H.; Nagao, Y.; Haruki, E. J. Chem. Soc., Chem. Commun. 1985, 501-502.

(12) Houlton, A.; Roberts, R. M. G.; Silver, J.; Wells, A. S.; Frampton, C. S. Acta Crystallogr. Sect. C 1992, 48, 1018-1022.

(13) Kündig, P.E.; Jeger, P.; Bernardinelli, G. Inorg. Chim. Acta 2004, 357, 1909-1919.

(14) Daifuku, S.L.; Kneebone, J.L.; Snyder, B.E.R.; Neidig, M.L. J. Am. Chem. Soc. 2015, 137, 11432-11444.

(15) Jefferis, J. M.; Girolami, G. S. Organometallics 1998, 17, 3630-3632. 
Insert Table of Contents artwork here

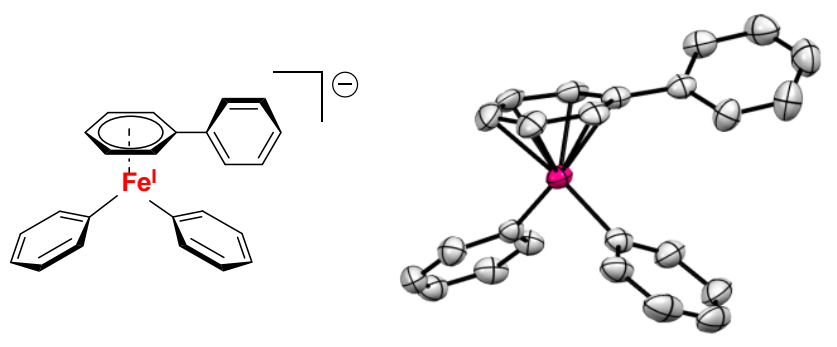

